\title{
Fiber Fuse Propagation Behavior
}

\author{
Shin-ichi Todoroki \\ National Institute for Materials Science \\ Japan
}

\section{Introduction}

A fiber fuse is the continuous self-destruction of optical fiber induced and fed by propagating light. It is triggered by the local heating of a waveguide structure through which a high power beam is being delivered. A typical example is seen along a single mode silica glass optical fiber delivering a few watts of light (see Fig. 1). Once heat-induced high density plasma (or an optical discharge) is captured in the core region, it travels along the fiber toward the light source, consuming the light energy and leaving a hollow damage train. Thus, this phenomenon imposes an inevitable limit on the light power per fiber for current optical communication systems, namely, the service be unable to meet the growing demands of communication traffic.

The first oral presentation describing the fiber fuse phenomenon was given by Kashyap (1988), followed by the first publication by Kashyap \& Blow (1988). These appeared just after certain

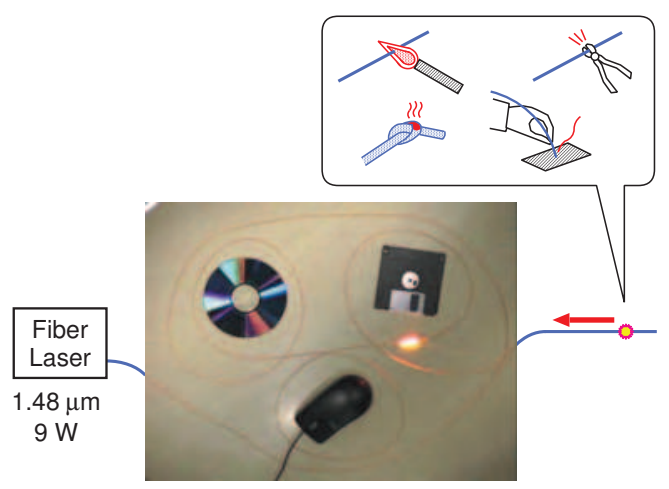

(a) Macroscopic view of fiber fuse propagation. The speed is about $1.2 \mathrm{~m} / \mathrm{s}$.

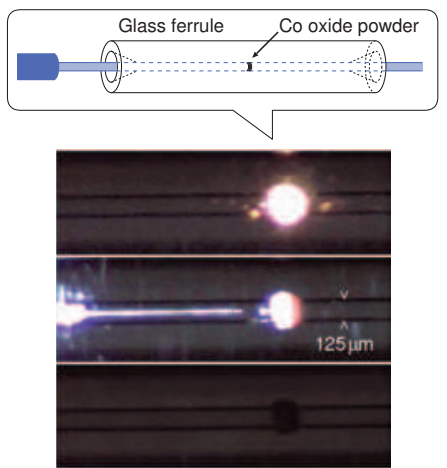

(b) Successive images of fiber fuse ignition (30 frames per second, Todoroki (2005d)).

Fig. 1. Captured video images of fiber fuse ignition and propagation along a single mode silica glass optical fiber pumped by a $9.0 \mathrm{~W}$ and $1.48 \mu \mathrm{m}$ laser light. See the original video at http:/ / www.youtube.com/watch?v=yjX5dU1EkTk (See also Table 3)

See http:/ /pubman.mpdl.mpg.de/pubman/item/escidoc:1058545 and 1058546 for errata and a Japanese translation, respectively. 
important milestones in optical communication, including the ultimate loss reduction of silica glass optical fibers by Kanamori et al. (1986) and the invention of Er-doped fiber amplifiers by Mears et al. (1987). Although this sensational phenomenon must have attracted some interest since its discovery, the number of related papers increased only after the turn of the century as a result of the rapid development of high power light sources (see Fig. 2).

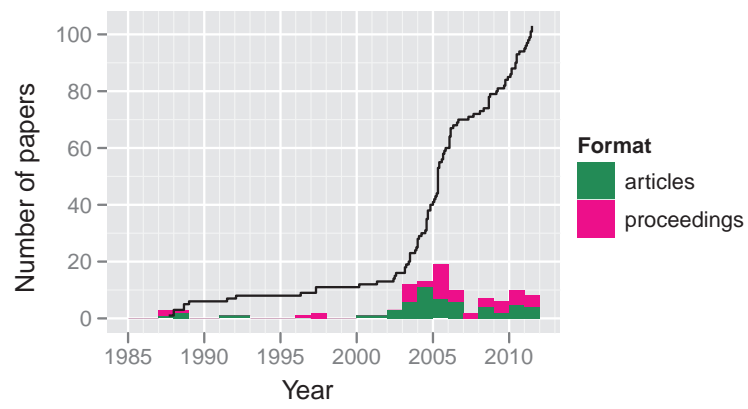

Fig. 2. Presentations and publications on the fiber fuse phenomenon. Total number (line) and yearly increments (bars). Source: http://www.geocities.jp/tokyo_1406/node3.html (See also Table 4)

Most of these researches were conducted from practical standpoints and have included techniques for the prevention and termination of a fiber fuse. In addition, studies from theoretical and/or microscopic viewpoints have been undertaken since 2003 (see Fig. 3). This paper briefly summarizes recent studies of macroscopic fiber fuse propagation where the fuse is regarded as a point without internal structures (Section 2) and the microscopic behavior of traveling plasma in relation to periodic void formation (Section 3). All the descriptions relate to silica-based fibers unless otherwise specified.

\begin{tabular}{c|c}
\multicolumn{2}{c}{ Macroscopic $(\$ 2)$} \\
$\begin{array}{c}\text { - Simulation } \\
\text { - Dissipative soliton } \\
\text { Shuto ('03), }\end{array}$ & $\begin{array}{c}\text { ・ Practical research } \\
\text { - Termination } \\
\text { Yakovlenko, }\end{array}$ \\
$\begin{array}{c}\text { Kashyap (87), Hand, } \\
\text { Akhmediev }\end{array}$ & Dianov, ..., \\
Abedin, ... \\
Theoretical & Experimental \\
\hline - Capillary instability & - In situ observation \\
Atkins ('03), & Todoroki ('04), \\
Yakovlenko & Bufetov \\
\multicolumn{2}{|c|}{ Microscopic (\$3) }
\end{tabular}

Fig. 3. Classification of fiber fuse studies with some key words and researchers.

\section{Macroscopic behavior}

\subsection{Fiber fuse initiation, propagation and damage}

Optical fibers were primarily developed to be transparent so that they would transmit light as far as possible. Therefore, at first it seems strange that transmitting light can actually destroy 
an optical fiber. However, it becomes reasonable when we consider that the absorption of the waveguide materials increases at elevated temperatures. Heat is the key to fiber fuse initiation.

Kashyap (1988) reported a steep increase in absorption over $1050^{\circ} \mathrm{C}$ through a one-meter-long Ge-doped single-mode silica glass fiber (see Fig. 4). Shuto et al. (2004a) suggested three factors as possible origins of this absorption: (i) point-defect (Ge $E^{\prime}$ center) formation (see Eqs. (1) and (2)), (ii) electronic conductivity due to the thermal ionization of a Ge-doped silica core (Eq. (2)), and (iii) the thermochemical production of $\mathrm{SiO}$ in silica glass (Eq. (3)). Davis et al. (1996) reported that the threshold power density required for fiber fuse initiation was of the order of $3 \mathrm{MW} / \mathrm{cm}^{-1}$ among typical single mode fibers operated at $1.06 \mu \mathrm{m}$ regardless of fiber type or core composition.

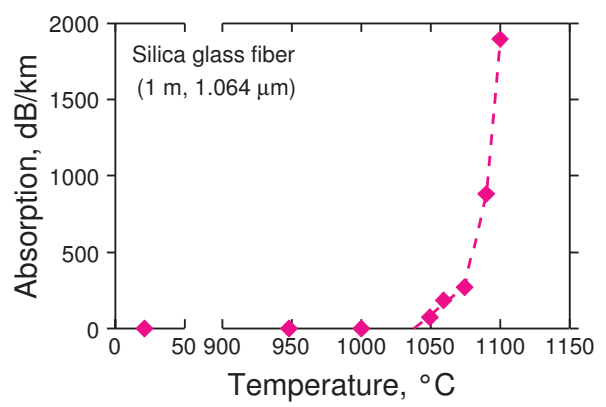

Fig. 4. Temperature dependence of the absorption in a single-mode Ge-doped silica glass fiber reported by Kashyap (1988).

$$
\begin{aligned}
& \underset{/}{\perp} \mathrm{Ge}-\mathrm{O}-\mathrm{Si}_{\perp}^{\prime} \longrightarrow-\underset{/}{\lfloor} \mathrm{Ge}-\mathrm{Si}_{\backslash}^{\prime}+\frac{1}{2} \mathrm{O}_{2} \uparrow
\end{aligned}
$$

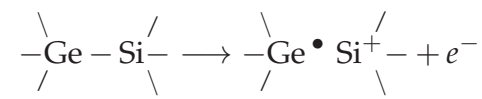

$$
\begin{aligned}
& \mathrm{SiO}_{2} \longrightarrow \mathrm{SiO}+\frac{1}{2} \mathrm{O}_{2} \uparrow \\
& \mathrm{SiO} \longrightarrow \mathrm{Si}+\mathrm{O} \longrightarrow \mathrm{Si}^{+}+\mathrm{O}^{+}+2 e^{-}
\end{aligned}
$$

Another seemingly strange characteristic of a fiber fuse is the propagation of a bright spot toward the light source. However, this is intuitively understandable if we compare it with a grassfire (see Fig. 5). A solitary wave of fire or plasma persists as an irreversible reaction region being fueled from the front, emitting light and heat all around, and leaving cinders or damage behind it. Such a solitary wave can be considered a "dissipative soliton" as discussed later.

In the fiber fuse reaction region, ionized gas plasma is enclosed by a molten glass layer, and this situation is maintained by the pump laser energy. Shuto (2010) mentioned that most of the plasma is generated through the reaction described by Eq. (4). The temperature is estimated to be more than a few thousand degrees Kelvin by Hand \& St. J. Russell (1988) and Dianov, Fortov, Bufetov, Efremov, Rakitin, Melkumov, Kulish \& Frolov (2006). 


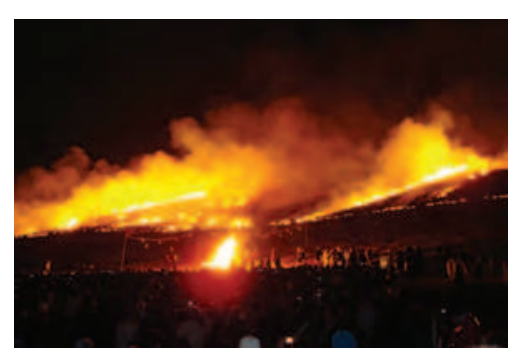

(a) Grassfire at Mt. Wakakusayama, a UNESCO World Heritage site, before the onset of spring in Nara, Japan. (C) Yoshitaka Inoue

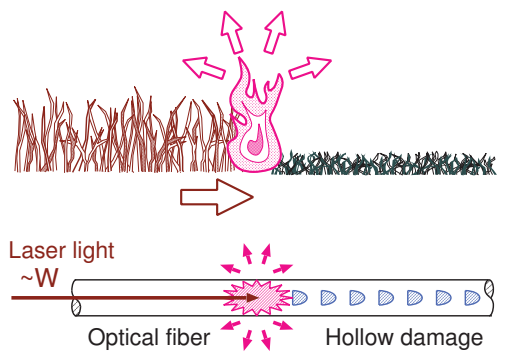

(b) Energy flows into/from a propagating reaction zone indicated with arrows.

Fig. 5. Comparison between grassfire and fiber fuse.

The propagation speed and pump power dependence of a fiber fuse have been investigated by many researchers. The speed is generally of the order of meters per second and increases almost linearly with pump laser power. However, Davis et al. (1997) pointed out that the slope vs. power density varies for different types of fibers.

As for the threshold power needed for fuse propagation, $P_{\text {th }}$, Dianov, Bufetov, Frolov, Plotnichenko, Mashinskii, Churbanov \& Snopatin (2002) pointed out that mode field diameter (MFD), $2 r_{\mathrm{s}}$, is the dominating factor, $i$. e., the threshold power density $\left(I_{\mathrm{th}}=P_{\mathrm{th}} / \pi r_{\mathrm{s}}^{2}\right)$ varies approximately inversely with the MFD for several types of fibers pumped at 1.06-1.48 $\mu \mathrm{m}$ (see also Bufetov \& Dianov (2005)). On the other hand, Seo et al. (2003) reported a linear relation between $P_{\text {th }}$ and MFD, which is parallel to the Dianov's relation. Table 1 lists the $P_{\text {th }}$ values for some standard silica based fibers.

\begin{tabular}{|c|c|c|c|c|c|}
\hline Fiber & $P_{\text {th }} / \mathrm{W}$ & $\lambda / \mu \mathrm{m}$ & $P_{\mathrm{th}} / \mathrm{W}$ & $\lambda / \mu \mathrm{m}$ & \\
\hline \multirow[t]{3}{*}{ SMF } & 1.0 & 1.064 & 1.4 & 1.467 & Seo et al. (2003) \\
\hline & & & $\sim 1.2$ & 1.48 & Todoroki (2005c) \\
\hline & & & 1.39 & 1.55 & Abedin \& Morioka (2009) \\
\hline \multirow[t]{2}{*}{ DSF } & 1.2 & 1.064 & 0.65 & 1.467 & Seo et al. (2003) \\
\hline & & & $\sim 1.1$ & 1.55 & Abedin (2009) \\
\hline$\overline{\mathrm{DCF}}$ & & & $\sim 0.7$ & 1.55 & Abedin (2009) \\
\hline
\end{tabular}

Table 1. Threshold power of fiber fuse propagation, $P_{\text {th }}$, for various fibers. See also Fig. 6 in Takenaga, Omori, Goto, Tanigawa, Matsuo \& Himeno (2008).

After the fiber fuse has passed, a hollow damage train is left behind, and the fiber is no longer able to guide light. Figure 6 shows an example of fuse damage; a fiber fuse propagated from right to left and terminated at the position shown by the arrow due to a gradual reduction in the pump power. The pair of horizontal lines surrounding these voids is the border of the region modified by the passage of the hot plasma. Its diameter is larger than the original core size seen on the left of the arrow and increases with the pump power.

Kashyap (1988) detected $\mathrm{O}_{2}$ gas inside the voids using Raman microscopy. The adjacent glass layer is expected to be densified. Dianov et al. (1992) provided supporting evidence, namely that refractive index around the void increased after the passage of the fiber fuse and subsequently decreased after fiber annealing for several seconds at about $1000^{\circ} \mathrm{C}$. 


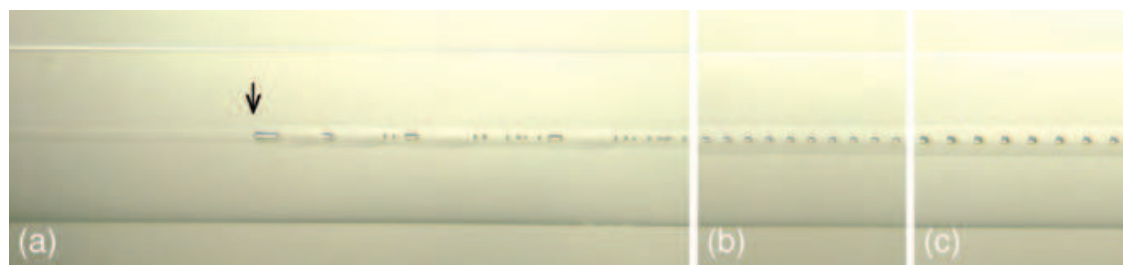

Fig. 6. Fiber fuse damage train in a standard single mode fiber (Corning SMF-28). After the ignition of the fiber fuse, the pump power of the laser $(1.48 \mu \mathrm{m})$ decreased from $7 \mathrm{~W}$ (c), 3.5 $\mathrm{W}(\mathrm{b})$ to $\sim 1.2 \mathrm{~W}$ (a) until its self-extinction at the position shown by the arrow.

The top of the void train provides a strong scattering point if the light is launched again. Yamada et al. (2011) warned that this scattered light heats and burns the surrounding coating and nylon jacket.

\subsection{Dissipative soliton and termination technology}

If we wish to avoid a fiber fuse, we should consider the energy flow into and from the traveling plasma. A "dissipative soliton" is a useful concept for this purpose and is defined by Akhmediev \& Ankiewicz (2005) as follows:

A dissipative soliton is a localized structure which exists for an extended period of time, even though parts of the structure experience gain and loss of energy and/or mass. . .

These solitons exist in "open" systems which are far from equilibrium.

Figure 7 compares a dissipative soliton and a conventional soliton that transfers energy and/or mass.
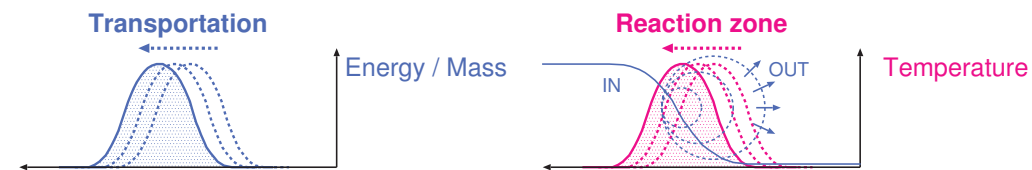

Fig. 7. Comparison of conventional and dissipative solitons.

On the basis of this energy flow, several researchers performed computer simulations of fiber fuse propagation and succeeded in reproducing the experimental propagation speed values. Their equations describing the energy flow are listed in Table 2. For the absorption coefficient, Rocha et al. (2009) used the Arrhenius form, $\alpha=\alpha_{0} \exp \left(-T^{\prime} / T\right)$, whereas other researchers used a custom function reproducing the steep temperature dependence shown in Fig. 4.

Shuto et al. (2004b) performed precise calculations using polar coordinates in which radiation heat loss appeared in the boundary condition. They also discussed the wavelength and power density dependence of the propagation speed. Akhmediev et al. (2008) described fiber fuse propagation as a "dissipative soliton" on the basis of a simple one dimensional calculation. Rocha et al. (2009) introduced a radiation loss term from the fiber surface and simulated three different types of fibers using MFD and $\alpha_{0}$ as parameters (see also Rocha et al. (2010)).

The dissipative soliton disappears when the supply of energy or matter is reduced, or the radiant heat and/or light is increased so that the system parameters move outside the range in which the soliton can exist. With a fiber fuse, it stops when the pumping power falls below the threshold power, $P_{\mathrm{th}}$, or when the energy removal is increased. This is the design principal behind "fiber fuse terminators", which have been proposed by many researchers. 


\section{Light-induced heat}

Diffusion

Radiation

Shuto et al. (2004b),

Golyatina et al. (2004): $\rho C_{\mathrm{p}} \frac{\partial T}{\partial t}=\quad \alpha(T) I \quad+\kappa\left(\frac{\partial^{2} T}{\partial z^{2}}+\frac{\partial^{2} T}{\partial r^{2}}+\frac{1}{r} \frac{\partial T}{\partial r}\right)$

$\begin{aligned} \text { Akhmediev et al. (2008): } \quad \frac{\partial T}{\partial t}= & \chi \alpha(T) I & +D \frac{\partial^{2} T}{\partial z^{2}} & -k\left(T-T_{0}\right) \\ \text { Rocha et al. (2009) : } \rho C_{\mathrm{p}} \frac{\partial T}{\partial t}= & \alpha_{\text {Arr }} I & +\kappa \frac{\partial^{2} T}{\partial z^{2}} & -\sigma_{\mathrm{s}} \epsilon_{\mathrm{e}}\left(T^{4}-T_{0}^{4}\right)\end{aligned}$

Table 2. Equations used for simulating fiber fuse propagation. $\rho$ : density, $C_{\mathrm{p}}$ : specific heat, $T$ : plasma temperature, $T_{0}$ : environment temperature, $\alpha(T)$ and $\alpha_{\text {Arr }}$ : absorption coefficient (see text), $\kappa$ : thermal conductivity, $\sigma_{\mathrm{s}}$ : Stefan-Boltzmann constant, $\epsilon_{\mathrm{e}}$ : surface emissivity.

Hand \& Birks (1989) demonstrated a fiber fuse termination at a special segment where the waveguide structure was modified to expand the pump laser beam (see Fig. 8 (a)). This is because a reduced power density in the core region exhausts the feed for the plasma. Later, Yanagi et al. (2003) developed a detachable device for practical use. However, we should note that this device cannot capture the fuse if the pump power exceeds the assumed limit.

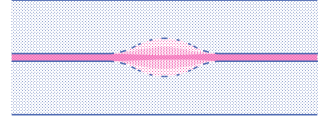

(a) Mode field expansion.

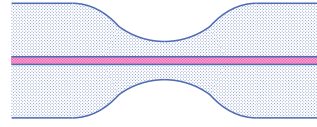

(b) Waist formation by etching.
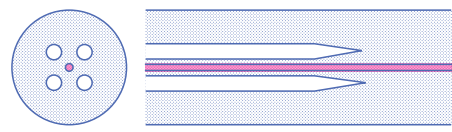

(c) Hole-assisted fiber spliced with conventional fiber.

Fig. 8. Waveguide structures for in-line fiber fuse terminators.

Dianov, Bufetov \& Frolov (2004) proposed a different structure in which the thickness of the cladding layer is reduced by chemical etching as illustrated in Fig. 8 (b). The fiber fuse is arrested here because its internal pressure cannot be maintained at this weakened segment and this causes deformation. Takenaga, Tanigawa, Matsuo, Fujimaki \& Tsuchiya (2008) discovered that fiber fuse propagation is not as easy in hole-assisted fibers (HAFs) as in conventional fibers. The termination occurs near the splice point of these fibers (see Fig. 8 (c)) and the penetration length into the HAF side increases as the pump power decreases. Thus, it is reasonable to consider that the holes release the internal pressure of the plasma to destabilize it. This behavior was directly observed by Hanzawa et al. (2010) with an ultra-high speed video camera. Recent proposals for devices using holey fibers are discussed in section 2.3.

Another approach to fiber fuse termination is to interrupt the light source after detecting a propagating fiber fuse. Abedin et al. (2009) proposed a remote detection method that employs a backreflected light from the void train (see Fig. 9 (a)). They found that characteristic signals appeared in optical coherence-domain reflectometry after the ignition of the fiber fuse.

Rocha et al. (2011) demonstrated a local detection technique that uses a fiber Bragg grating as a temperature sensor placed in thermal contact with the propagation line (see Fig. 9 (b)). A heat pulse of a few degrees centigrade was detected as an increase in the Bragg wavelength monitored with an optical interrogator. 


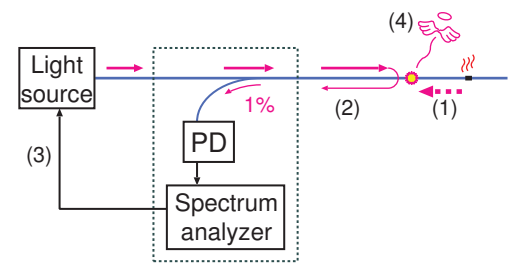

(a) Backreflected light detection.

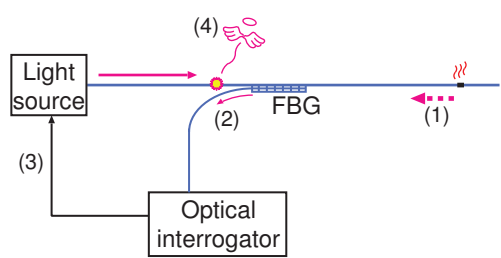

(b) Monitoring temperature increase.

Fig. 9. Schematic diagram of fiber fuse terminator. (1) propagation after ignition, (2) signal detection, (3) interruption of the light source and (4) termination.

\subsection{Fiber fuse under special conditions}

A fiber fuse can be initiated not only with a CW laser but also with a pulsed laser. Kashyap (1988) reported that mode locking has little effect on the velocity of damage propagation, but does alter the shape of the periodic voids. Dianov, Fortov, Bufetov, Efremov, Frolov, Schelev \& Lozovoi (2006) demonstrated a detonation-like propagation mode with velocities up to 3 $\mathrm{km} / \mathrm{s}$ that appeared when a Q-switched laser was used for pumping (wavelength: $1.064 \mu \mathrm{m}$, pulse repetition frequency: $5 \mathrm{kHz}$, pulse duration: $250 \mathrm{~ns}$, pulse energy: up to $0.6 \mathrm{~mJ}$, and maximum pulse power: $3.0 \mathrm{~kW}(3.8 \mathrm{~W}$ average)). Traveling plasma appeared only for a pulse duration and the damage included large cracks with a diameter up to $120 \mu \mathrm{m}$.

There have been several reports on non-conventional fibers. Lee et al. (2006) investigated fuse propagation over polarization-maintaining fibers and found that the power threshold for fast axis alignment is larger than that for slow axis alignment. Wang et al. (2008) showed some damage photographs of crack propagation in double-clad fiber for high power use.

Photonic crystal fibers (PCFs) also allow fiber fuse propagation. However, Dianov, Bufetov, Frolov, Chamorovsky, Ivanov \& Vorobjev (2004) demonstrated that their threshold power is approximately ten times higher than that for conventional fibers. The reason is apparently the same as that discussed for HAFs above; the air holes reduce the plasma density. Thus, it is possible to use this fiber to make a fiber fuse terminator. Kurokawa \& Hanzawa (2011) observed a fuse termination in situ at a splice point between PCF and conventional fiber. Ha et al. (2011) proposed another terminator using a hollow optical fiber.

Dianov, Bufetov, Frolov, Mashinskii, Plotnichenko, Churbanov \& Snopatin (2002) reported the destruction of chalcogenide and fluoride glass fibers pumped at less than $1 \mathrm{~W}$. They observed a distraction wave without plasma that thermally decomposed the entire cross section of the fiber. This is because these materials decompose at a much lower temperature than silica glass.

\section{Microscopic behavior}

Another characteristic behavior of a fiber fuse is the formation of periodic bullet-shaped voids. These voids are formed just after the passage of running plasma, and this has been experimentally confirmed by ultra-high speed photography (Bufetov \& Dianov (2005); Bufetov et al. (2005), or see Fig. 10).

Two ideas have been proposed for the driving force behind this void formation. Atkins et al. (2003) suggested that Rayleigh instability, or positive surface tension, minimizes the interface area between plasma and molten glass following the analogy of falling water droplets and an air jet in a fluid (see Fig. 11). On the other hand, Yakovlenko (2004) pointed out that this idea has certain inadequacies, that is, it overlooks the high viscosity of molten silica and the 

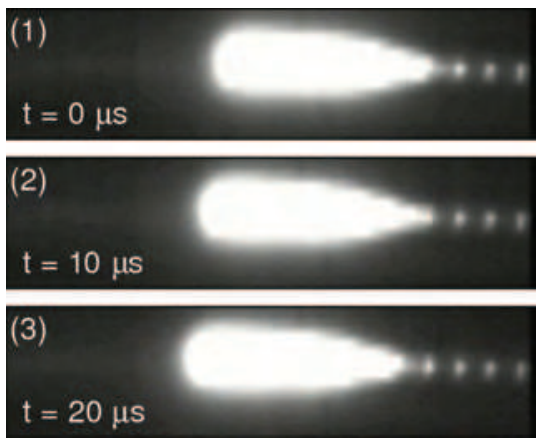

Fig. 10. Ultra-high speed photographs of fiber fuse propagation pumped with $9 \mathrm{~W} 1.48 \mu \mathrm{m}$ light (Todoroki (2005b)). Discrete scattering points from the periodic voids ( $22 \mu \mathrm{m}$-interval) are clearly seen after the running plasma.

disappearance of surface tension at the elevated temperatures. Instead, he mentioned the electrostatic repulsion between negative charge layers induced at the plasma-liquid interface (see also Yakovlenko (2006a)). However, neither idea can explain why the voids look like bullets. Although Yakovlenko (2006b) pointed out that a bullet shape appeared in his simulated temperature profile of a running plasma, there is no description of its periodic appearance in the time domain.
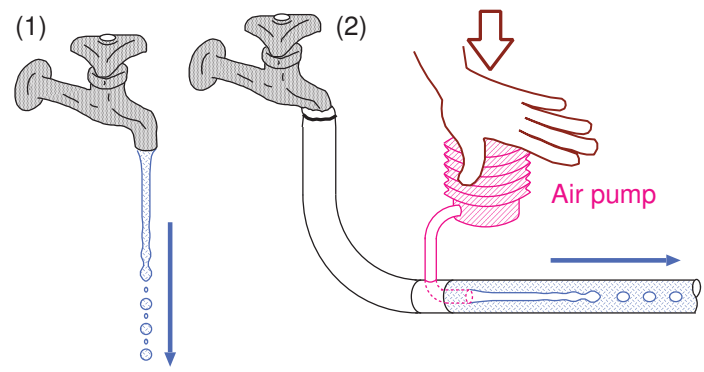

Fig. 11. Examples of jet breakdown due to Rayleigh instability, (1) A jet of water broken up into droplets (see Isenberg (1992) p. 131) and (2) a bubble train in a water flow (see Chandrasekhar (1981) p. 540).

Meanwhile, I have been investigating the mechanism of periodic void formation through an experiment-based approach, namely, a morphological analysis of void shapes and ultra-high speed photography. Section 3.1 discusses the requirements for periodic void formation. Then, the quench-induced deformation of the hollow melt is clarified by a statistical analysis of damage photographs (Section 3.2). Finally, the mechanism of bullet-like void formation is proposed (Section 3.3). All the discussion relates to silica-based step-indexed single-mode optical fibers unless otherwise specified.

\subsection{Pump power dependence of hollow damage morphology}

We should note that not all the fused damages has the appearance of periodic bullets. Figure 12 shows the front part of a fused damage train that remained in Corning SMF-28 fibers after the light sources had been turned off (1.2-9 W, $1.48 \mu \mathrm{m}$, CW; Todoroki (2005c)). Bullet-shaped 
periodic voids appear when the pump power exceeds $2 \mathrm{~W}$ (see (a)-(d)) or $\sim 1.3 \mathrm{~W}$ (g) near the propagation threshold. The latter mode is very unsteady with respect to fluctuations in laser power and/or waveguide structure, i. e. the periodicity disappears easily and sometimes the fuse vanishes ${ }^{1}$. For the former stable mode, the interval of the periodic voids increases with the pump power and a long and narrow void is left at the top of the damage train.
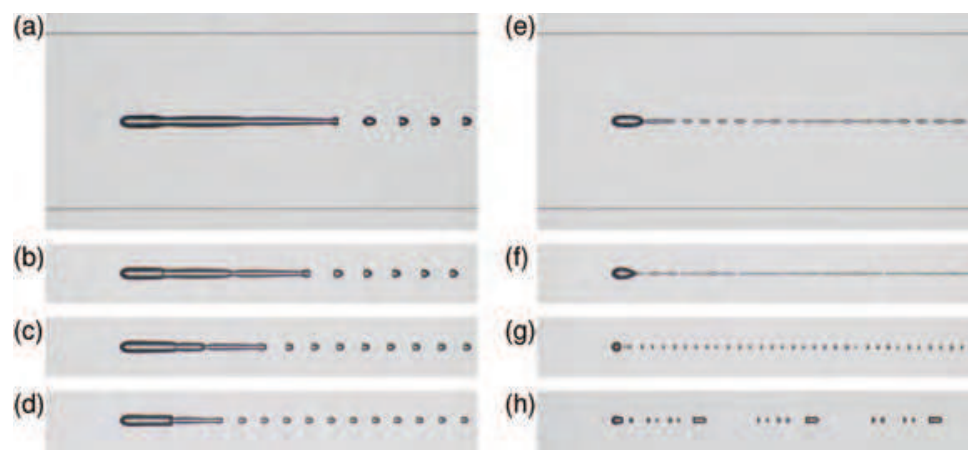

Fig. 12. Optical micrographs showing the front part of the fiber fuse damage generated in single-mode silica glass fibers (Corning SMF-28). The powers of the pump laser $(1.48 \mu \mathrm{m})$ are (a) $9.0 \mathrm{~W}$, (b) $7.0 \mathrm{~W}$, (c) $5.0 \mathrm{~W}$, (d) $3.5 \mathrm{~W}$, (e) $2.0 \mathrm{~W}$, (f) $1.5 \mathrm{~W}$, (g) 1.3 W, and (h) 1.2 W. The thin two lines at the top and bottom of (a) and (e) are the edges of the $125 \mu \mathrm{m}$ diameter fiber. (Todoroki (2005c))

These top voids are valuable evidence for exploring the state of traveling plasma. In fact, these photographs show good agreement with the in-situ image of fiber fuse propagation shown in Fig. 13. In both cases, the shape along the axial direction is asymmetric when the pump power exceeds $2 \mathrm{~W}$. Thus, this asymmetric shape is expected to be the origin of the stable periodic void formation. However, these in-situ images provide no further information about the void formation process owing to their poor resolution. Thus, the shape of the damage sites are analyzed instead in the next subsection.

\subsection{Deformation of hollow melt during quenching}

The period of one void formation is estimated to be a few tens of microseconds based on the propagation speed and void interval. For example, the periodic voids shown in Fig. 12 (a)-(d) were generated every $18.7 \mu \mathrm{s}(9 \mathrm{~W})-25.4 \mu \mathrm{s}(3.5 \mathrm{~W})$. During this period, the plasma was found to propagate at a constant speed (Todoroki (2005a)). Since the damage structure varies according to the moment at which the light source is turned off during this cycle, at least 40 samples were prepared in order to collect a variety of damage patterns.

In addition, to maximize the quenching rate of the melt, a fiber fuse was terminated in a segment where the colored nylon jacket $(0.9 \mathrm{~mm} \phi)$ over the cladding had been removed beforehand (about $20 \mathrm{~cm}$ at the maximum). This is because color pigments in the nylon jacket scatters the visible radiation from the inside and the backscattered light is re-absorbed by the melt with absorptive species shown in Eqs. (1)-(3) to generate heat. This light-heat conversion

\footnotetext{
${ }^{1}$ For example, see the video in Fig. 2 of Todoroki (2005d) in which the fuse stopped after it passed through a splicing point in a jacket-free segment.
} 

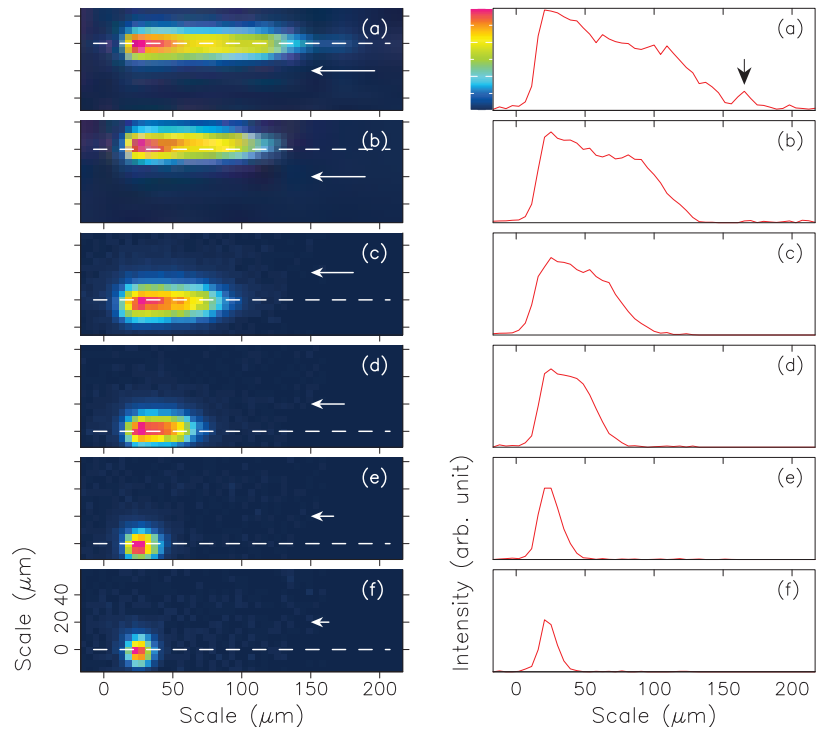

Fig. 13. Ultrahigh-speed photograph of visible light emission from a fiber fuse (left, gray-scale image is converted to colored-scale image, exposure time: $1 \mu \mathrm{s}$ ) and intensity profiles along the dashed line in each image (right). The powers of the pump laser $(1.48 \mu \mathrm{m})$ are (a) $9.0 \mathrm{~W}$, (b) $7.0 \mathrm{~W}$, (c) $5.0 \mathrm{~W}$, (d) $3.5 \mathrm{~W}$, (e) $2.0 \mathrm{~W}$, and (f) $1.5 \mathrm{~W}$. Each horizontal arrow indicates the distance that the plasma moves in $40 \mu \mathrm{s}$. (Todoroki (2005c))

occurs throughout the fiber fuse propagation but is absent in the bare fiber segment just before the fiber fuse termination ${ }^{2}$.

To compare the damage sites precisely, the void size should be properly normalized because it varies sensitively with the pump power. For example, the interval of the periodic voids, $\Lambda$, among the 81 samples pumped with $9 \mathrm{~W} 1.48 \mu \mathrm{m}$ light ranged from $21.7 \mu \mathrm{m}$ to $22.7 \mu \mathrm{m}$. This must be due to the fluctuation of pump laser power and the loss of the fiber between the fuse and the light source. Thus, the following two parameters are defined on the basis of $\Lambda$,

$$
x_{1}^{\prime}=x_{1} / \Lambda, \quad l_{2}^{\prime}=l_{2} / \Lambda
$$

where $x_{1}$ is a parameter describing the top position of the first void in a virtual scale graduated on $\Lambda$ (see the vertical lines in Fig. 14) and $l_{2}$ is the length of the second void.

The left column in Fig. 15 ((1) -(6)) shows selected photographs of the samples pumped with $9 \mathrm{~W} 1.48 \mu \mathrm{m}$ light. They are sorted in order of increasing $x_{1}^{\prime}$, with the intention of rearranging them in chronological order within the void formation cycle (Todoroki $(2005 \mathrm{a} ; \mathrm{c})$ ). The sorted photographs suggest that $l_{2}^{\prime}$ has a tendency to decrease with increasing $x_{1}^{\prime}$ (see the inset table). This correlation among all the 40 samples is shown on the left in Fig. 16.

The sequence of the photographs seems to capture the moment at which the long top void is divided in two by a melt bridge (Todoroki $(2005 a ; c)$ ). However, we should not overlook a possibility that these structures are the result of the modification that occurred during the fiber

\footnotetext{
2 The plasma decay time in a bare fiber is reported to be less than $7 \mu$ s (Todoroki (2005a)). Detailed description of this light-heat conversion will be published soon (Todoroki (2011)).
} 


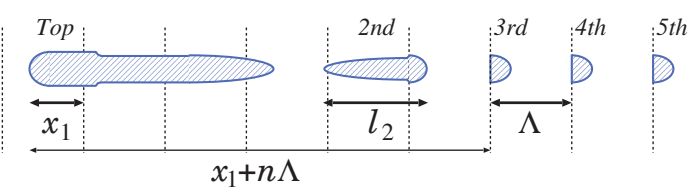

Fig. 14. Definition of the parameters used in Eq. (5). The vertical lines are placed at the bottom of bullet-like voids at intervals of $\Lambda$. Then, the distance between the top of the first void and periodic voids is written as $x_{1}+n \Lambda$ ( $n$ : natural number).

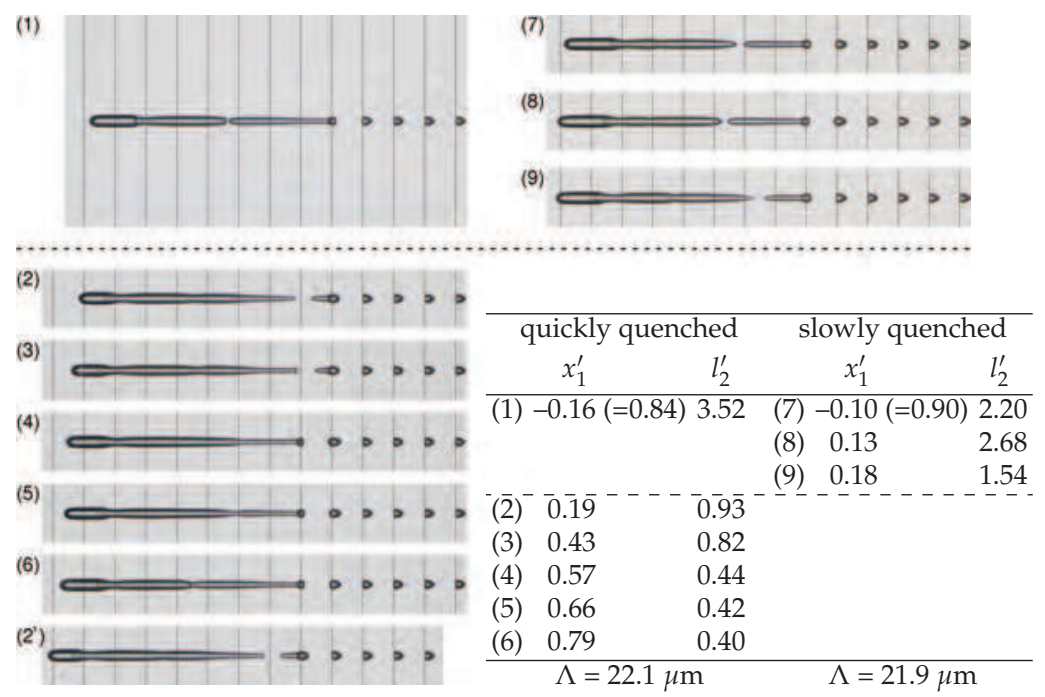

Fig. 15. Optical micrographs of the damage sites pumped with $9 \mathrm{~W} 1.48 \mu \mathrm{m}$ light. (1) - (6): samples whose quenching point has no plastic coating, and (7) - (9): with coating (see text). The photograph at the bottom $\left(2^{\prime}\right)$ is the same as that at the top (2), shifted $22.1 \mu \mathrm{m}$ to the left. The inset table lists the size parameters defined in Eq. (5), that are plotted as red points in Figs. 16 and Fig. 17.

fuse quenching period. Fortunately, the histogram of $l_{2}^{\prime}$ shown in the right of Fig. 16 provides a clue to this problem. That is, the $l_{2}^{\prime}$ distribution is strongly biased below 1.0. In other words, void structures like (1) shown in Fig. $15\left(l_{2}^{\prime}>1.0\right)$ appeared less frequently than (2) - (6).

If these void structures are stable during quenching, the $l_{2}^{\prime}$ distribution is expected to be independent on the quenching rate. Thus, another set of the samples was prepared in which a fiber fuse was quenched in a colored nylon jacketed segment with an outer diameter of 0.9 $\mathrm{mm}$. Hereafter, they are referred to as 'slowly quenched' whereas the previous samples were referred to as 'quickly quenched'. The result shown in Fig. 17 is clearly different from that shown in Fig. 16; the correlation between $x_{1}^{\prime}$ and $l_{2}^{\prime}$ became considerably weaker and the $l_{2}^{\prime}$ histogram became relatively flat.

This behavior is well explained by an assumption that the melt surrounding the plasma tends to form a bridge inside the cavity after the plasma has been extinguished and before the melt is frozen (see the lower white arrow in Fig. 18 between (3-a) and (c)). In other words, after the quench begins, a melt with a long hollow space $\left(l_{2}^{\prime}<1\right)$ becomes unstable and forms a bridge inside the cavity $\left(l_{2}^{\prime}>1\right)$. In this case, the bridge position is influenced very little by 

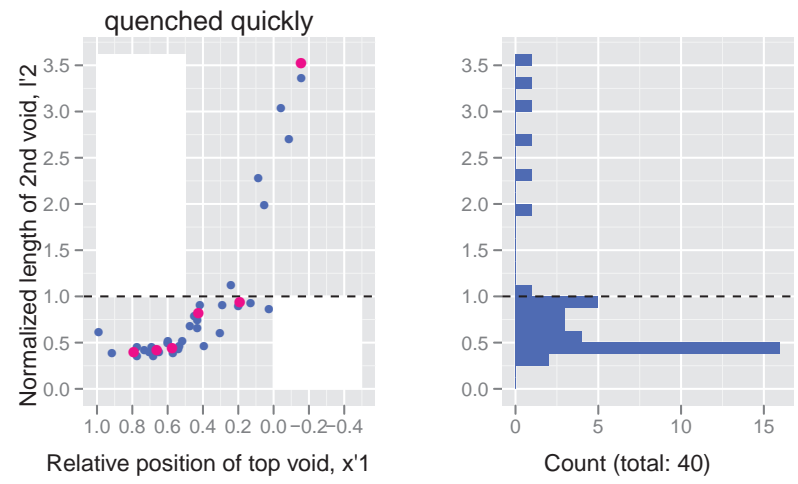

Fig. 16. Correlation between $x_{1}^{\prime}$ and $l_{2}^{\prime}$ (left) and histogram of $l_{2}^{\prime}$ (right) for the samples pumped with $9 \mathrm{~W} 1.48 \mu \mathrm{m}$ light in which the fiber fuse was extinguished in a coating-free segment (see text). The red points are the results for samples (1) - (6) shown in Fig. 15.
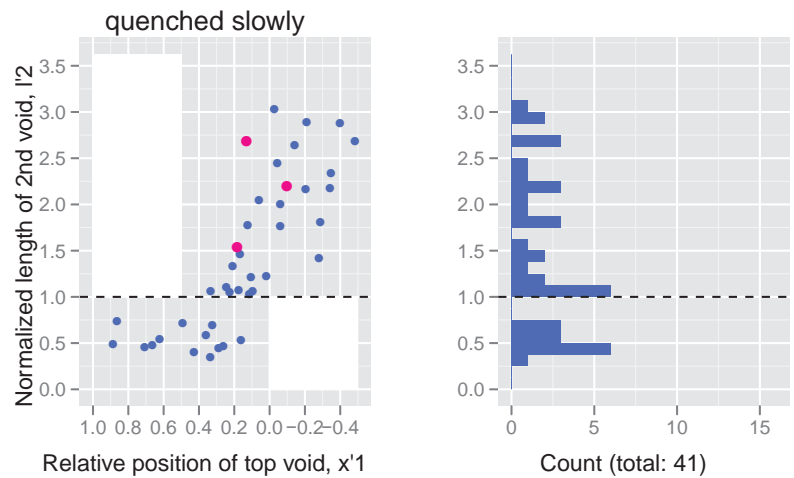

Fig. 17. Correlation between $x_{1}^{\prime}$ and $l_{2}^{\prime}$ (left) and histogram of $l_{2}^{\prime}$ (right) for the samples pumped with $9 \mathrm{~W} 1.48 \mu \mathrm{m}$ light in which the fiber fuse was extinguished in a coated segment (see text). The red points are the results for samples for (7) - (9) shown in Fig. 15.

the moment at which the power is turned off, and there is little correlation between $x_{1}^{\prime}$ and $l_{2}^{\prime}$ in the resulting structures. In addition, the bridge width in the slowly quenched samples is larger than that of the quickly quenched samples (compare Fig. 15 (7) - (9) and (1)). This suggests that bridge growth was promoted by slow quenching.

Possible driving forces for this bridge formation are, firstly, the sudden pressure/temperature decrease in the hollow cavity that occurs as a result of the laser power being switched off and the subsequent deposition of quenched gas, and secondly, the negative surface tension of glass melt (Yakovlenko (2006b)). The temperature dependence of the surface tension is given by Eötvös formula, $\gamma(T)=k(\rho / M)^{2 / 3}\left(T_{\text {cr }}-T\right)$, where $k$ is a constant, $\rho$ density, $M$ molar weight, and $T_{\text {cr }}$ critical temperature. Although the experimental data for the silica melt are not available, Yakovlenko (2006b) mentioned that the tension is expected to be negative at elevated temperatures (more than $\sim 3000 \mathrm{~K}$ ) and surface creation promoted. 


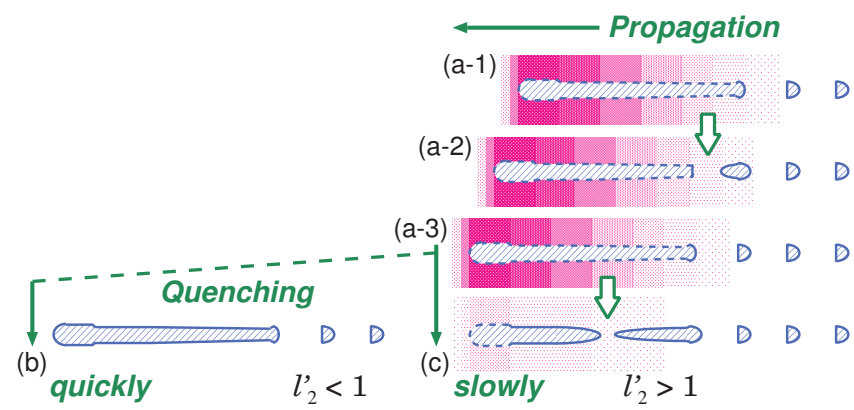

Fig. 18. Model of void formation during propagation and quenching of fiber fuse. Bridge formation is shown by white arrows.

The bridge that remained in the quickly quenched samples with $l_{2}^{\prime}>1$ as in Fig. 15 (1) were probably formed after the power had been turned off. The low probability of the samples with $l_{2}^{\prime}>1$ shown on the right in Fig. 16 supports this hypothesis. Moreover, this is confirmed by the recent result that I obtained by the in-situ videography of fiber fuse propagation shown in the left of Fig. 19. If there is a bridge before quenching, i. e. during propagation, no light emission is expected from the bridge. However, the centers of the intensity profiles have no dark regions.
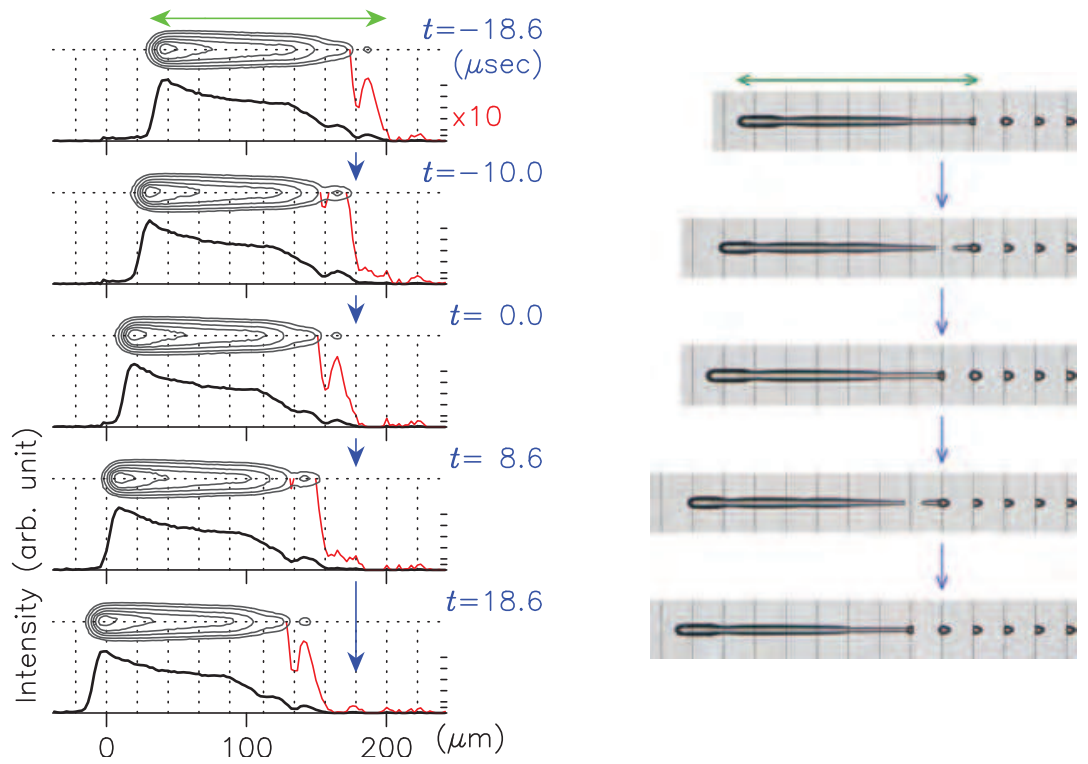

Fig. 19. Intensity profiles of visible light emission from a fiber fuse propagating through a single-mode optical fiber pumped by $9 \mathrm{~W} 1.48 \mu \mathrm{m}$ light (left, exposure time: $0.37 \mu \mathrm{s}$ ) and photographs of hollow damage for comparison, generated under the same condition (right). The vertical line interval is $22 \mu \mathrm{m}$. The vertical dashed lines are placed on the scattering points from the periodic voids. The photographs are the same as those shown in Fig. 15 (2) and (4). 
This is more clearly recognized when we compare these profiles with the void photographs as shown on the right. These photographs are arranged to coincide with the in situ images with respect to the following two points; (1) the full width of the profile matches the length of the top void (see the green arrows on the top) and (2) the weak scattering points on the vertical dashed line match the top of the periodic voids on the vertical solid line. The blue arrows are reference points for this comparison.

Consequently, the melt surrounding the traveling plasma tends to form a bridge inside the cavity after the light source has been turned off. However, this action is suppressed by fast quenching (see Fig. 18 (b)). Therefore, the damage photographs of quickly quenched samples without such a bridge (see Fig. 15 (2) - (6)) constitute useful data for discussing the periodic process of fiber fuse propagation in the next subsection.

\subsection{Bridge formation during fiber fuse propagation}

According to the sequence in Fig. 15 (2) - (6), the bridge formation process occurs between (6) and $\left(2^{\prime}\right)$. The hottest region of the plasma passed this position $\sim 120 \mu$ s earlier and the temperature is decreasing. Its quenching rate is much slower than that induced by suddenly turning off the light source because the hot plasma is still alive nearby and is moving away at about $1 \mathrm{~m} / \mathrm{s}(=1 \mu \mathrm{m} / \mu \mathrm{s})$. Thus, this situation, illustrated in Fig. 18 (a-1) and (a-2), is almost the same as the slow quenching case (see the lower white arrow) except that the bridge is compressed by the hot plasma.

This compression explains why the periodic voids look like bullets. This process is frozen in the photographs shown in Fig. 15 (2) - (6). After a bridge appears, the detached void begins to shrink due to the pressure from the hot plasma until the surrounding melt solidifies. Since the rear side of the new void solidifies earlier than the front, the rear shape remains round whereas the front becomes flatter.

It is interesting to find that an early sign of bridge formation is recorded in the in-situ observation result shown on the left in Fig. 19. A weak modulation appeared on the tail of the light emission profile and its interval is the same as that of the periodic voids. However, it appeared only when the pump power was $9 \mathrm{~W}$ (see the black arrow in Fig. 13). This modulation may suggest the instability of the plasma or the surrounding melt as proposed by Atkins et al. (2003) (Rayleigh instability) and Yakovlenko (2004) (induced electrostatic repulsion) but further study is needed.

The void formation sequence can be modified by controlling certain external conditions. Bufetov et al. (2008) observed a large-scale periodic void train in an optical fiber that allows the interference of the $\mathrm{LP}_{01}$ and $\mathrm{LP}_{02}$ modes. Figure 20 shows the void train surrounded by a region of modified refractive index. Its interval was found to coincide with that of the interference pattern.

Todoroki (2008) reported the breakage of the periodic void pattern over hetero-core splice points as shown in Fig. 21. Traveling plasma temporarily stopped forming voids when the core was expanded from HI 1600 to SMF-28e, whereas it left some long voids when the core size was reduced. It is interesting to find a similar tendency in Bufetov's case at the inflection points of the interference. That is, the void train disappears at the segment where the mode field is increasing (see dashed lines b in Fig. 20), and a long void appears where the mode field is reduced (see dashed lines a). Moreover, some of the voids have a flat area whose direction is opposite to that of the regular bullet-like voids (see arrows in Figs. 20 and 21). This behavior must be due to the modulated internal pressure of the plasma. To clarify the mechanism, 


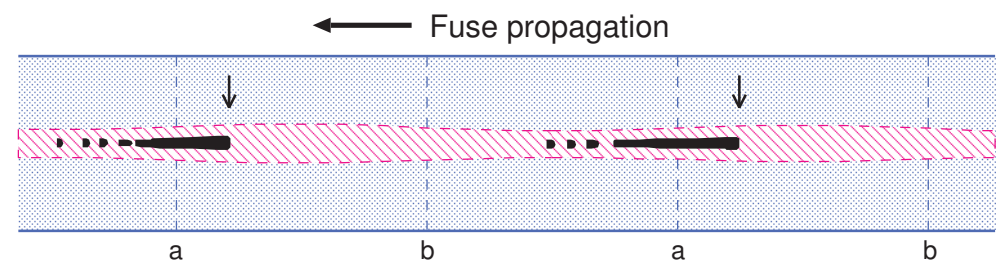

Fig. 20. Illustration of large-scale periodic void train left in an optical fiber allowing the interference of two propagation modes of $1.07 \mu \mathrm{m}$ light. This is reproduced from a photograph in Bufetov et al. (2007). The diameter of the fiber cladding is $125 \mu \mathrm{m}$. The vertical dashed lines are on the inflection points of the modified refractive-index area shown as a red hatched region.

further investigation is needed including the in-situ observation of traveling plasma and a statistical analysis of quickly quenched void samples.

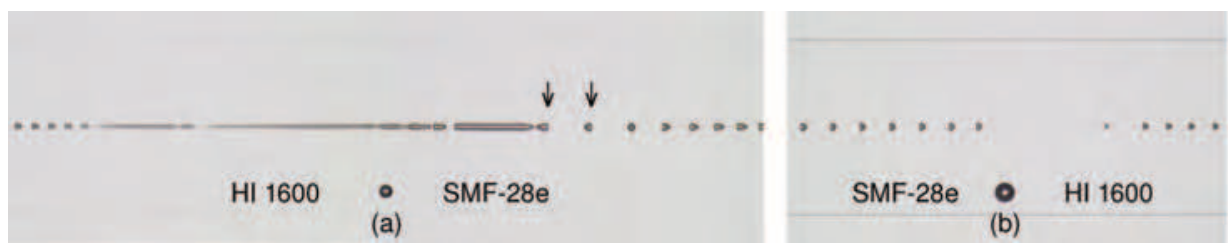

Fig. 21. Photographs of fiber fuse damage over the splicing point between HI 1060 and SMF-28e (Corning). The hollow spheres in the cladding are located at the border between two fibers and were accidentally captured during splicing. The fuse was initiated with $9 \mathrm{~W}$ $1.07 \mu \mathrm{m}$ light that propagates in a multi-mode through SMF-28e.

\section{Summary}

Knowledge accumulated about fiber fuse propagation since 1988 is briefly summarized. From a macroscopic viewpoint, the dissipative soliton concept and an analogy with grassfire help us understand this strange phenomenon. The strong heat-induced absorption of silica glass and the highly confined supply of laser energy cause captured plasma to shift to the light source along the fiber leaving catastrophic damage behind it. From a microscopic viewpoint, the periodic void formation process was unveiled by the statistical analysis of void shapes and ultra-fast videography. The bullet-like shape of the damage train results from the formation of an intrinsic bridge inside the hollow silica melt behind the traveling plasma and the successive compression of detached voids under a steep temperature gradient along the fiber.

\section{Acknowledgements}

I am grateful to Mr. Keisuke Aizawa, Mr. Arata Mihara and Mr. Yousuke Suzuki (Photron Ltd.) for helping with the ultrahigh-speed videography experiment. 


\begin{tabular}{lccc}
\hline & Todoroki (2005c) & Todoroki (2005d) & Todoroki (2008) \\
\hline Ignition: & Fig. 1, Fig. 3* & Fig. 3* & - \\
Propagation: & - & Fig. 2, Fig. 7* & Movie S1* \& S2* \\
Self-termination: & Fig. 7 & - & - \\
Void formation model: $^{\dagger}$ & - & - \\
\hline
\end{tabular}

Table 3. Fiber fuse video clips available on the net. *: Ultra-high speed video, ${ }^{\dagger}$ : outdated because all the samples were slowly quenched (see Section 3.2).

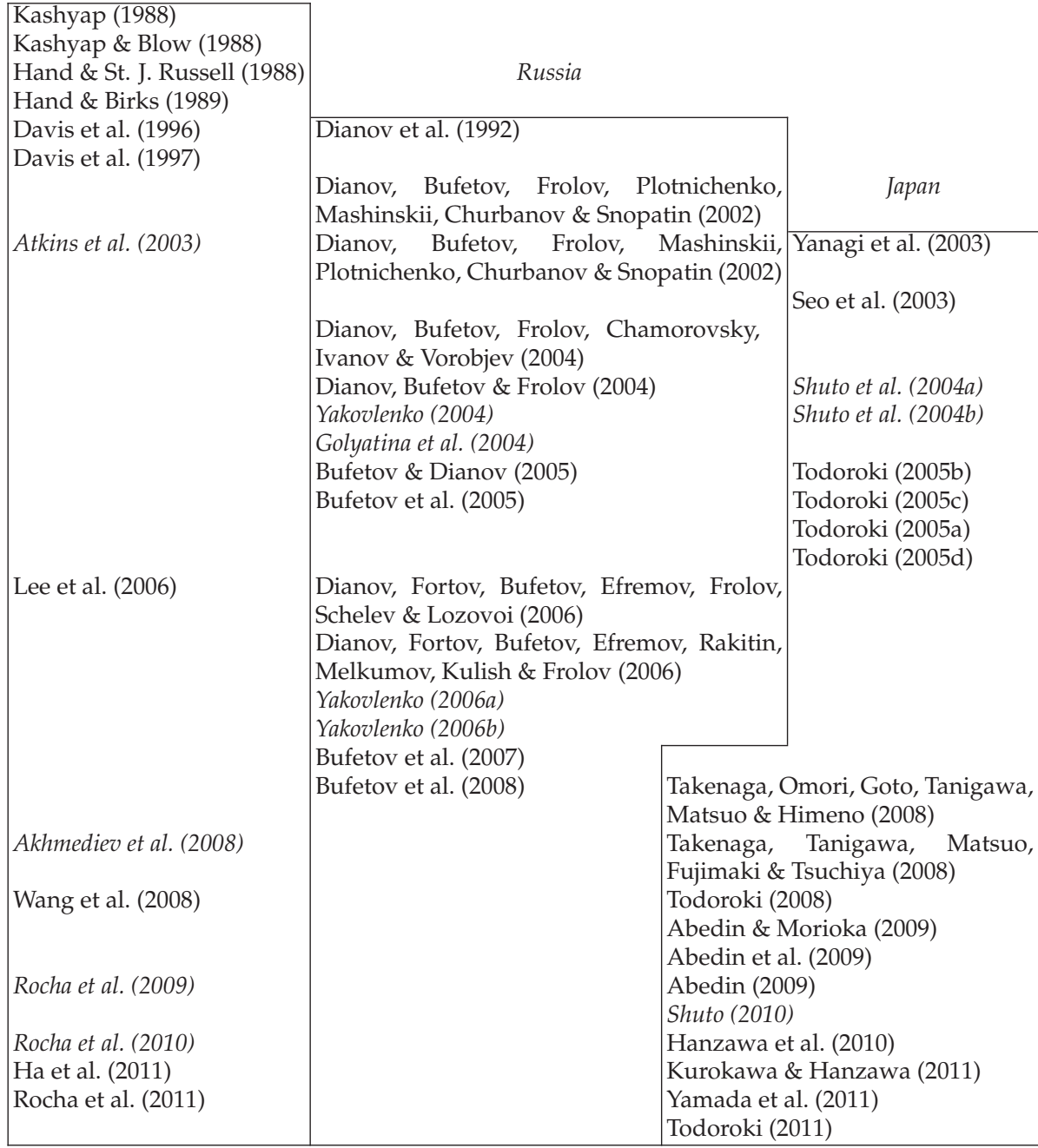

Table 4. Chronological table of fiber fuse research cited in this paper. Theoretical works are given in italics. 


\section{References}

Abedin, K. S. (2009). Remote sensing of fiber fuse propagation using RF detection, The Technical Report of The Proceedings of The Institute of Electronics, Information and Communication Engineers, OPE, Optoelectronics 109(159): 43-46.

Abedin, K. S. \& Morioka, T. (2009). Remote detection of fiber fuse propagating in optical fibers, Proceedings of Optical Fiber Communication/National Fiber Optic Engineers Conference. (OThD5).

Abedin, K. S., Nakazawa, M. \& Miyazaki, T. (2009). Backreflected radiation due to a propagating fiber fuse, Optics Express 17(8): 6525-6531.

Akhmediev, N. \& Ankiewicz, A. (2005). Dissipative solitons in the complex Ginzburg-Landau and Swift-Hohenberg equations, Dissipative Solitons, Vol. 661 of Lecture Notes in Physics, Springer-Verlag, Berlin, pp. 1-17.

Akhmediev, N., St. J. Russell, P., Taki, M. \& Soto-Crespo, J. M. (2008). Heat dissipative solitons in optical fibers, Physics Letters A 372(9): 1531-1534.

Atkins, R. M., Simpkins, P. G. \& Yablon, A. D. (2003). Track of a fiber fuse: a Rayleigh instability in optical waveguides, Opt. Lett. 28(12): 974-976.

Bufetov, I. A. \& Dianov, E. M. (2005). Optical discharge in optical fibers, Physics-Uspekhi 48(1): 91-94.

Bufetov, I. A., Frolov, A. A., Dianov, E. M., Fortov, V. E. \& Efremov, V. P. (2005). Dynamics of fiber fuse propagation, Optical Fiber Communication Conference, 2005. Technical Digest. OFC/NFOEC, Vol. 4, Anaheim, CA. (OThQ7).

Bufetov, I. A., Frolov, A. A., Shubin, A. V., Likhachev, M. E., Lavrishchev, C. V. \& Dianov, E. M. (2007). Fiber fuse effect: New results on the fiber damage structure, Proceedings of the 33rd European Conference on Optical Communication, Vol. 1, IEE's Photonics Professional Network, Berlin, Germany, pp. 79-80. (Mon 1.5.2).

Bufetov, I. A., Frolov, A. A., Shubin, A. V., Likhachev, M. E., Lavrishchev, S. V. \& Dianov, E. M. (2008). Propagation of an optical discharge through optical fibres upon interference of modes, Quantum Electronics 38(5): 441-444.

Chandrasekhar, S. (1981). Hydrodynamic and Hydromagnetic Stability, International Series of Monographs on Physics (Oxford, England), Dover Publications.

Davis, D. D., Mettler, S. C. \& DiGiovani, D. J. (1996). Experimental data on the fiber fuse, in H. E. Bennett, A. H. Guenther, M. R. Kozlowski, B. E. Newnam \& M. J. Soileau (eds), 27th Annual Boulder Damage Symposium: Laser-Induced Damage in Optical Materials: 1995, Vol. 2714 of SPIE Proceedings, SPIE, pp. 202-210. (Boulder, CO, USA, 30 Oct. 1995).

Davis, D. D., Mettler, S. C. \& DiGiovani, D. J. (1997). A comparative evaluation of fiber fuse models, in H. E. Bennett, A. H. Guenther, M. R. Kozlowski, B. E. Newnam \& M. J. Soileau (eds), Laser-Induced Damage in Optical Materials: 1996, Vol. 2966 of SPIE Proceedings, SPIE, pp. 592-606. (Boulder, CO, USA, 7 Oct 1996).

Dianov, E. M., Bufetov, I. A. \& Frolov, A. A. (2004). Destruction of silica fiber cladding by the fuse effect, Opt. Lett. 29(16): 1852-1854.

Dianov, E. M., Bufetov, I. A., Frolov, A. A., Chamorovsky, Y. K., Ivanov, G. A. \& Vorobjev, I. L. (2004). Fiber fuse effect in microstructured fibers, IEEE Photon. Technol. Lett. 16(1): 180-181. 
Dianov, E. M., Bufetov, I. A., Frolov, A. A., Mashinskii, V. M., Plotnichenko, V. G., Churbanov, M. F. \& Snopatin, G. E. (2002). Catastrophic destruction of fluoride and chalcogenide optical fibers, Electron. Letters 38(15): 783-784.

Dianov, E. M., Bufetov, I. A., Frolov, A. A., Plotnichenko, V. G., Mashinskii, V. M., Churbanov, M. F. \& Snopatin, G. E. (2002). Catastrophic destruction of optical fibres of various composition caused by laser radiation, Quantum Electron. 32(6): 476-478.

Dianov, E. M., Fortov, V. E., Bufetov, I. A., Efremov, V. P., Frolov, A. A., Schelev, M. Y. \& Lozovoi, V. I. (2006). Detonation-like mode of the destruction of optical fibers under intense laser radiation, J. Exp. Theo. Phys. Lett. 83(2): 75-78.

Dianov, E. M., Fortov, V. E., Bufetov, I. A., Efremov, V. P., Rakitin, A. E., Melkumov, M. A., Kulish, M. I. \& Frolov, A. A. (2006). High-speed photography, spectra, and temperature of optical discharge in silica-based fibers, IEEE Photon. Technol. Lett. 18(6): 752-754.

Dianov, E. M., Mashinskii, V. M., Myzina, V. A., Sidorin, Y. S., Streltsov, A. M. \& Chickolini, A. V. (1992). Change of refractive index profile in the process of laser-induced fiber damage, Sov. Lightwave Commun. 2: 293-299.

Golyatina, R. I., Tkachev, A. N. \& Yakovlenko, S. I. (2004). Calculation of velocity and threshold for a thermal wave of laser radiation absorption in a fiber optic waveguide based on the two-dimensional nonstationary heat conduction equation, Laser Physics 14(11): 1429-1433.

Ha, W., Jeong, Y. \& Oh, K. (2011). Fiber fuse effect in hollow optical fibers, Opt. Lett. 36(9): 1536-1538.

Hand, D. P. \& Birks, T. A. (1989). Single-mode tapers as 'fibre fuse' damage circuit-breakers, Electron. Lett. 25(1): 33-34.

Hand, D. P. \& St. J. Russell, P. (1988). Solitary thermal shock waves and optical damage in optical fibers: the fiber fuse, Opt. Lett. 13(9): 767-769.

Hanzawa, N., Kurokawa, K., Tsujikawa, K., Matsui, T., Nakajima, K., Tomita, S. \& Tsubokawa, M. (2010). Suppression of fiber fuse propagation in hole assisted fiber and photonic crystal fiber, J. Lightwave Technology 28(15): 2115-2120.

Isenberg, C. (1992). The Science of Soap Films and Soap Bubbles, new edn, Dover Publications.

Kanamori, H., Yokota, H., Tanaka, G., Watanabe, M., Ishiguro, Y., Yoshida, I., Kakii, T., Itoh, S., Asano, Y. \& Tanaka, S. (1986). Transmission characteristics and reliability of pure-silica-core single-mode fibers, J. Lightwave Technology 4(8): 1144-1150.

Kashyap, R. (1988). Self-propelled self-focusing damage in optical fibres, Lasers '87; Proc. the Tenth Int. Conf. Lasers and Applications, STS Press, McLean, VA, pp. 859-866. (Lake Tahoe, NV, Dec. 7-11, 1987).

Kashyap, R. \& Blow, K. J. (1988). Observation of catastrophic self-propelled self-focusing in optical fibres, Electron. Lett. 24: 47-49.

Kurokawa, K. \& Hanzawa, N. (2011). Fiber fuse propagation and its suppression in hole-assisted fibers, IEICE Transactions on Communications E94.B(2): 384-391.

Lee, M. M., Roth, J. M., Ulmer, T. G. \& Cryan, C. V. (2006). The fiber fuse phenomenon in polarization-maintaining fibers at $1.55 \mu \mathrm{m}$, Proc. of the Conference on Lasers and Electro-Optics (CLEO). (JWB66).

Mears, R. J., Reekie, L., Jauncey, I. M. \& Payne, D. N. (1987). Low-noise erbium-doped fibre amplifier operating at $1.54 \mu \mathrm{m}$, Electronics Letters 23(19): 1026-1028.

Rocha, A. M., Antunes, P. F. C., Domingues, M. F. F., Facão, M. \& André, P. S. (2011). Detection of fiber fuse effect using FBG sensors, IEEE Sensors Journal 11(6): 1390 -1394. 
Rocha, A. M., Facão, M. \& André, P. S. (2010). Study of fiber fuse effect on different types of single mode optical fibers, in D. Faulkner (ed.), NOC/OCEI 2010 Proceedings : 15th European Conference on Networks and Optical Communications and 5th Conference on Optical Cabling and Infrastructure (ISBN: 9789729341939), Universidade do Algarve, Faro-Algarve, Portugal, pp. 71-75. (Presented on June 10).

Rocha, A. M., Facão, M., Martins, A. \& André, P. S. (2009). Simulation of fiber fuse effect propagation, International Conf. on Transparent Networks - Mediterranean Winter, 2009, Angers, France. (FrP.12).

Seo, K., Nishimura, N., Shiino, M., Yuguchi, R. \& Sasaki, H. (2003). Evaluation of high-power endurance in optical fiber links, Furukawa Review (24): 17-22.

Shuto, Y. (2010). Evaluation of high-temperature absorption coefficients of ionized gas plasmas in optical fibers, IEEE Photon. Technol. Lett. 22(3): 134-136.

Shuto, Y., Yanagi, S., Asakawa, S., Kobayashi, M. \& Nagase, R. (2004a). Evaluation of high-temperature absorption coefficients of optical fibers, IEEE Photon. Technol. Lett. 16(4): 1008-1010.

Shuto, Y., Yanagi, S., Asakawa, S., Kobayashi, M. \& Nagase, R. (2004b). Fiber fuse phenomenon in step-index single-mode optical fibers, IEEE J. Quantum Electronics 40(8): 1113-1121.

Takenaga, K., Omori, S., Goto, R., Tanigawa, S., Matsuo, S. \& Himeno, K. (2008). Evaluation of high-power endurance of bend-insensitive fibers, Proceedings of Optical Fiber Communication/National Fiber Optic Engineers Conference. (JWA11).

Takenaga, K., Tanigawa, S., Matsuo, S., Fujimaki, M. \& Tsuchiya, H. (2008). Fiber fuse phenomenon in hole-assisted fibers, Proceedings of the 34th European Conference on Optical Communication, Vol. 5, pp. 27-28. (P.1.14).

Todoroki, S. (2005a). Animation of fiber fuse damage, demonstrating periodic void formation, Opt. Lett. 30(19): 2551-2553.

Todoroki, S. (2005b). In-situ observation of fiber-fuse propagation, Jpn. J. Appl. Phys. 44(6A): 4022-4024.

Todoroki, S. (2005c). Origin of periodic void formation during fiber fuse, Optics Express 13(17): 6381-6389.

Todoroki, S. (2005d). Transient propagation mode of fiber fuse leaving no voids, Optics Express 13(23): 9248-9256.

Todoroki, S. (2008). In situ observation of modulated light emission of fiber fuse synchronized with void train over hetero-core splice point, PLoS ONE 3(9): e3276.

Todoroki, S. (2011). Threshold power reduction of fiber fuse propagation through a white tight-buffered single-mode optical fiber, IEICE Electronics Express 8 (accepted).

Wang, J., Gray, S., Walton, D. \& Zenteno, L. (2008). Fiber fuse in high-power optical fiber, in M.-J. Li, P. Shum, I. H. White \& X. Wu (eds), Passive Components and Fiber-based Devices V, Vol. 7134 of SPIE Proceedings, SPIE, pp. 71342E-1-9. (Hangzhou, China).

Yakovlenko, S. I. (2004). Plasma behind the front of a damage wave and the mechanism of laser-induced production of a chain of caverns in an optical fibre, Quantum Electron. 34(8): 765-770.

Yakovlenko, S. I. (2006a). Mechanism for the void formation in the bright spot of a fiber fuse, Laser Physics 16(3): 474-476.

Yakovlenko, S. I. (2006b). Physical processes upon the optical discharge propagation in optical fiber, Laser Physics 16(9): 1273-1290. 
Yamada, M., Koyama, O., Katsuyama, Y. \& Shibuya, T. (2011). Heating and burning of optical fiber by light scattered from bubble train formed by optical fiber fuse, Proceedings of Optical Fiber Communication/National Fiber Optic Engineers Conference. (JThA1).

Yanagi, S., Asakawa, S., Kobayashi, M., Shuto, Y. \& Naruse, R. (2003). Fiber fuse terminator, The 5th Pacific Rim Conference on Lasers and Electro-Optics, Vol. 1, p. 386. (W4J-(8)-6, Taipei. Taiwan, 22-26 Jul. 2003). 


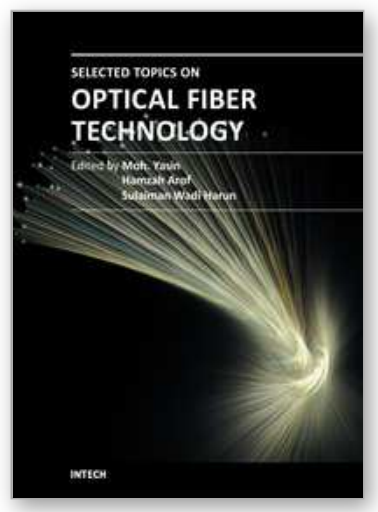

\author{
Selected Topics on Optical Fiber Technology \\ Edited by Dr Moh. Yasin
}

ISBN 978-953-51-0091-1

Hard cover, 668 pages

Publisher InTech

Published online 22, February, 2012

Published in print edition February, 2012

This book presents a comprehensive account of the recent advances and research in optical fiber technology. It covers a broad spectrum of topics in special areas of optical fiber technology. The book highlights the development of fiber lasers, optical fiber applications in medical, imaging, spectroscopy and measurement, new optical fibers and sensors. This is an essential reference for researchers working in optical fiber researches and for industrial users who need to be aware of current developments in fiber lasers, sensors and other optical fiber applications.

\title{
How to reference
}

In order to correctly reference this scholarly work, feel free to copy and paste the following:

Shin-ichi Todoroki (2012). Fiber Fuse Propagation Behavior, Selected Topics on Optical Fiber Technology, Dr Moh. Yasin (Ed.), ISBN: 978-953-51-0091-1, InTech, Available from:

http://www.intechopen.com/books/selected-topics-on-optical-fiber-technology/fiber-fuse-propagation-behavior

\section{INTECH}

open science | open minds

\section{InTech Europe}

University Campus STeP Ri

Slavka Krautzeka 83/A

51000 Rijeka, Croatia

Phone: +385 (51) 770447

Fax: +385 (51) 686166

www.intechopen.com

\section{InTech China}

Unit 405, Office Block, Hotel Equatorial Shanghai

No.65, Yan An Road (West), Shanghai, 200040, China

中国上海市延安西路65号上海国际贵都大饭店办公楼 405 单元

Phone: +86-21-62489820

Fax: $+86-21-62489821$ 
(C) 2012 The Author(s). Licensee IntechOpen. This is an open access article distributed under the terms of the Creative Commons Attribution 3.0 License, which permits unrestricted use, distribution, and reproduction in any medium, provided the original work is properly cited. 